\title{
Retraction
}

\section{Retraction: Tremere et al, "Mechanistic Basis and Functional Roles of Long-Term Plasticity in Auditory Neurons Induced by a Brain-Generated Estrogen"}

The Journal of Neuroscience has received a report from Northwestern University that describes substantial data misrepresentation in the article "Mechanistic Basis and Functional Roles of Long-Term Plasticity in Auditory Neurons Induced by a Brain-Generated Estrogen" by Liisa A. Tremere, Ryan F. Kovaleski, Kalping Burrows, Jin Kwon Jeong, and Raphael Pinaud, which appeared on pages $16478-16495$ of the November 14, 2012 issue. Because the results cannot be considered reliable, J Neurosci is retracting the paper.

DOI:10.1523/JNEUROSCI.1554-15.2015 